\title{
Cellular Concrete Bricks with Recycled Expanded Polystyrene Aggregate
}

\author{
Juan Bosco Hernández-Zaragoza, ${ }^{1}$ Teresa López-Lara, ${ }^{1}$ Jaime Horta-Rangel, ${ }^{1}$ \\ Carlos López-Cajún, ${ }^{1}$ Eduardo Rojas-González, ${ }^{1}$ F. J. García-Rodríguez, ${ }^{2}$ and Jorge Adue ${ }^{3}$ \\ ${ }^{1}$ Universidad Autónoma de Querétaro, Facultad de Ingeniería, Cerro de las Campanas S/N, Col. Las Campanas, 76010, QRO, Mexico \\ ${ }^{2}$ Instituto Tecnológico de Celaya, Departamento de Ingeniería Industrial, Avenida García Cubas 1200 Esquina Ignacio Borunda, \\ 38010 Celaya, GTO, Mexico \\ ${ }^{3}$ Universidad Nacional de Rosario, Instituto de Mecánica Aplicada y Estructura (IMAE), Facultad de Ciencias Exactas, \\ Ingeniería y Agrimensura, Riobamba y Berutti S/N, 2000 Rosario, Argentina
}

Correspondence should be addressed to Teresa López-Lara; lolte@uaq.mx

Received 20 May 2013; Revised 2 October 2013; Accepted 16 October 2013

Academic Editor: Alex Li

Copyright ( 2013 Juan Bosco Hernández-Zaragoza et al. This is an open access article distributed under the Creative Commons Attribution License, which permits unrestricted use, distribution, and reproduction in any medium, provided the original work is properly cited.

\begin{abstract}
Cellular concrete bricks were obtained by using a lightweight mortar with recycled expanded polystyrene aggregate instead of sandy materials. After determining the block properties (absorption, compressive strength, and tensile stresses), it was found that this brick meets the requirements of the masonry standards used in Mexico. The obtained material is lighter than the commercial ones, which facilitates their rapid elaboration, quality control, and transportation. It is less permeable, which helps prevent moisture formation retaining its strength due to the greater adherence shown with dry polystyrene. It was more flexible, which makes it less vulnerable to cracking walls due to soil displacements. Furthermore, it is economical, because it uses recyclable material and has properties that prevent deterioration increasing its useful life. We recommend the use of the fully dry EP under a dry environment to obtain the best properties of brick.
\end{abstract}

\section{Introduction}

A lightweight mortar can be produced in different ways and basically depends on the air factor, that is, decreasing the density of a material consists in including air in its structure, which can be done by replacing the coarse aggregate (sand) by air. Thus, the air inclusion in the material structure favors the formation of bubbles (empty space) inside the concrete or mortar. Therefore, when it dries out, the air holes generate a lightweight material. This type of concrete is known as Cellular Concrete. It has been suggested to define a lightweight concrete as a concrete made with lightweight aggregate or without aggregates that allow to obtain a weight less than conventional concrete of $2400 \mathrm{~kg} / \mathrm{m}^{3}$ [1].

With regard to the use of the polystyrene in concretes, literature mentions the use of expanded polystyrene (EP) beads as lightweight aggregate both in concretes and mortars containing silica fume a supplementary cementitious material. The resulting concretes were seen to have densities varying from 1500 to $2000 \mathrm{~kg} / \mathrm{m}^{3}$, with the corresponding strengths varying from 10 to $21 \mathrm{MPa}$ [2]. Another study covers the use of expanded polystyrene (EPS) and unexpanded polystyrene (UEPS) beads as lightweight aggregate in concretes that contain fly ash as a supplementary cementitious material. Lightweight concrete with wide range of concrete densities $\left(1000-1900 \mathrm{~kg} / \mathrm{m}^{3}\right)$ were studied mainly for compressive strength, split tensile strength, moisture migration, and absorption. The results indicate that for comparable aggregate size and concrete density, concrete with UEPS aggregate exhibited $70 \%$ higher compressive strength than EPS aggregate [3].

Fine silica fume greatly improved the bond between the EP beads and cement paste and increased the compressive strength of EP concrete. The research showed that EPS concrete with a density of $800-1800 \mathrm{~kg} / \mathrm{m}^{3}$ and a compressive strength of $10-25 \mathrm{MPa}$ can be made by partially replacing 
coarse and fine aggregate by EPS beads. In addition, adding steel fiber significantly improved the drying shrinkage [4].

Another investigation shows the comparison between the mechanical properties of EP concretes containing fly ash with the literature results on concretes containing ordinary Portland cement alone as the binder [5]. A research proposes the development of a class of structural grade polystyrene aggregate concrete with a wide range of concrete densities between 1400 and $2100 \mathrm{~kg} / \mathrm{m}^{3}$ through partial replacement of coarse aggregate with polystyrene aggregate in control concrete [6].

Styrene-butadiene rubber latex as a polymeric admixture was applied in lightweight expanded polystyrene (EP) concrete. The effects of curing conditions and polymercement ratio on the compressive and flexural strengths of polymer-modified EP concretes were investigated [7]. Hardened concrete containing chemically treated expanded polystyrene beads showed that the strength, stiffness, and chemical resistance of polystyrene aggregate concrete of a constant density were affected by the water to cement ratio [8].

In the first part of this research, based on the definition and characteristics of a lightweight concrete, a low-density recyclable material was searched, such that could be recycled using a cheap sustainable recycling method. This material was the expanded polystyrene (EP). With this material, it a mortar was produced in which the coarse aggregates were substituted completely by low-density particles. So, bricks are composed of recycled expanded polystyrene as aggregate and commercial Portland cement as binder. Unlike most of the works published in the literature, this mortar does not use pozzolans or additives or additional aggregates. In this previous study, this material had a good adherence with the hydrated cement and the best mechanical properties in the cellular concrete were obtained for a water/cement ratio of 0.4 and $600 \mathrm{~g}$ of expanded polystyrene [9].

In the second stage, the core of this research, and with the defined technology, a specific technological application of the mortar of recycled material was the making of cellular bricks. These should be competitive on price, quality, and mechanical and physical properties against the current ones on the market. Furthermore, the cellular bricks should use a recyclable material in a sustainable fashion.

\section{Methods and Techniques}

The activities listed below allowed the fabrication and the mechanical and physical evaluation of the cellular-concrete bricks;

(i) getting and milling of the EP;

(ii) application of the water/cement ratio of 0.4 ;

(iii) realization of the cellular concrete;

(iv) fabrication of bricks using steel molds of $6 \times 10 \times 20 \mathrm{~cm}$;

(v) unmolding and obtaining the dry-weight of the bricks;

(vi) absorption, Compressive, and Tensile tests; ASTM C67-03a Standard includes the three tests [10]; (vii) report of results;

(viii) comparison of the results with the reported values of some commercial bricks in Mexico.

Compressive strength of expanded polystyrene (EPS) lightweight concrete increases significantly with a decrease in EPS bead size $[11,12]$. Adding, another study includes three sizes of polystyrene particles $(1,2.5$, and $6.3 \mathrm{~mm})$ in concrete and concludes that the size of $1 \mathrm{~mm}$ has greater resistance to compression [12]. Then, as the goal of the project was to reuse a recyclable material such as expanded polystyrene, the particle sizes depended on the sustainable and cheap milling process. In fact, the sizes achieved (2-4 mm) were very close to those reported as greater compressive strength [12].

In first place, the search of EP waste materials was carried out. These EP residuals were from items obtained mainly from computers packing. Once the material was collected, it was milled with water in a kitchen blender, because without water there was no milling. Resulting particle size was 2$4 \mathrm{~mm}$. Then, the excess of water was eliminated and EP was dried at the natural environment, without using ovens.

In agreement with previous studies, the cellular concrete was obtained by mixing $600 \mathrm{~g}$ of polystyrene and a water/cement ratio of 0.4 . The cement used was a CPC (composite Portland cement).

It should be pointed out that one of the important factors that influenced this research was the high environmental humidity in the place where this research was realized (Rosario, Argentina). This fact led to the result of a fluid composite that allowed easily the filling of the steel molds.

Two types of specimens, labeled as A and B with dimensions of $100 \times 200 \times 60 \mathrm{~mm}$, were tested. Type A had a water/cement ratio of 0.4 , a weight of $0.600 \mathrm{Kg}$ of EP in semihumid state, and an age of 28 days. Type B had the same water/cement ratio, but with $0.520 \mathrm{Kg}$ weight of semidry EP. The B test age was only 14 days because of the end of the project.

Due to environmental humidity circumstances, when we dry the wet polystyrene (resultant material for milling process) to 7 days, we obtained weights of $600 \mathrm{~g}$ for bricks $\mathrm{A}$ and B. Immediately we elaborate the bricks A (with $600 \mathrm{~g}$ ) in the first stage of the project. Then, as the remaining polystyrene was used 28 days later, we noticed that the weight had decreased. Therefore this remaining material was divided and used in five bricks B. So the bricks B had $520 \mathrm{~g}$ of polystyrene. Therefore bricks A were prepared with "semihumid" polystyrene and bricks B with "semidry" polystyrene. We did not obtain a fully dry weight of EP because of the condition of environmental local dampness.

Environmental humidity levels for "semihumid" and "semidry" polystyrene were the same; the difference was the exposure time under those conditions. Environmental humidity of the place was 62-95\% [14] in the days of the experiment (Rosario, Argentina; August 2012). The polystyrene named "semihumid" was exposed 7 days under this environment and 28 days for the "semidry."

After 27 days for bricks A and 13 days for bricks B, the absorption test was performed to the bricks (this experimental test requires $24 \mathrm{~h}$ [10] of saturation of the bricks for 
TABLE 1: Statistical evaluation of absorption (\%), Compressive and tensile strength (MPa) of A and B.

\begin{tabular}{lcccccc}
\hline Property & Number of data & Mean & Median & Variance & Standard deviation & Coefficient of variation, \% \\
\hline Absorption, A & 6 & 9.328 & 9.135 & 0.842 & 0.917 & 9.84 \\
Absorption, B & 6 & 4.464 & 4.21 & 0.284 & 0.533 & 11.95 \\
Compressive strength, A & 5 & 9.69 & 9.3 & 0.840 & 0.916 & 9.46 \\
Compressive strength, B & 5 & 6.916 & 7.28 & 0.598 & 0.773 & 11.18 \\
Tensile strength, A & 6 & 2.195 & 2.22 & 0.254 & 0.503 & 22.95 \\
Tensile strength, B & 5 & 1.632 & 1.64 & 0.002 & 0.046 & 2.85 \\
\hline
\end{tabular}

its evaluation). Therefore, the absorption test results were obtained at 28 days for bricks A and at 14 days for bricks B with the Compressive and Tensile tests.

Theoretically, if kept in a moist environment, about $90 \%$ of its strength is gained in the first 28 days. The main criterion for evaluating the compressive strength of concrete is the strength of the concrete on 28th day. The concrete sample is tested after 28 days and the result of this test is considered as a criterion for quality and rigidity of that concrete [15].

\section{Results and Discussion}

Statistical evaluation of the percentage of absorption of $\mathrm{A}$ and $\mathrm{B}$ are shown in Table 1. For measuring the absorption property, the ASTM C67-03a standard specifies that the material is kept immersed in water for 24 hours [10]. The percentage of absorption was determined by (1) [10]. Dry and saturated weights $\left(W_{d}\right.$ and $W_{s}$, resp.) of the brick were before and after its saturation, respectively:

$$
\% \text { Absorption }=100 \frac{\left(W_{s}-W_{d}\right)}{W_{d}} .
$$

From Table 1 we observed that brick B (semidry EP) has less absorption than brick A (semihumid EP). Although the time of study of brick B is half of A, the trend to increase absorption is very little. Thus, it is apparent that this material could diminish the moisture generated in walls built with other types of bricks, which the absorption is greater due to the type of aggregates being used, such as sand.

Statistical results of the compressive tests [10] to both types of specimens, of area $100 \times 200 \mathrm{~mm}$, are shown in Table 1. It should be recalled that bricks A were 28 days old, whereas bricks B were 14 days old. Because of the above, the differences in strength could be justified. It can also be observed that the trend in the increase of strength continues in specimens $B$, and it is would overcome the value reached by specimens of the type $A$, due to the greater adherence (less absorption) created by the semidry EP.

The tensile strength or Modulus of Rupture [10] was computed as

$$
S=\frac{3 W(L / 2-x)}{b d^{2}}
$$

where $S$ is tensile strength or Modulus of Rupture (MPa), W is applied maximum load $(\mathrm{kg}), L$ is distance between supports (cm) (computed as the specimen length minus 2 inches, because the supports are at distance of 1 inch from each end), $x$ is horizontal distance from the point of application of the load to the place where the fissure arises $(\mathrm{cm})$, and $b$ and $d$ are width and thickness of the specimen, respectively $(\mathrm{cm})$.

Statistical results of the Tensile test of specimen types A and B are shown in Table 1. These were determined from (2).

From Table 1 the Mean of tensile strength for specimens $\mathrm{A}$ and $\mathrm{B}$ are 2.195 and $1.632 \mathrm{MPa}$, respectively. Specimen type $\mathrm{B}$ showed a partial tensile strength with relation to the one that can develop in 28 days.

Assuming traditional concrete bricks with coarse aggregates and burned clay bricks have very low values of tensile strength, approximately $0.8 \mathrm{MPa}$ in average [13]. Thus, EP provides flexural properties to the brick that contribute to wall stability, especially when it has ascending and descending movements caused by problematic soils such as expansive and collapsible soils, phreatic water level changes, and earthquakes, among others. Therefore, this material reduces the appearance of cracks in the wall. This aspect had not been considered in the fabrication of traditional bricks.

Concrete can hardly be considered to be homogeneous because the properties of its constituents are different and it is, to some extent, anisotropic. Nevertheless, the fracture mechanics approach helps to understand the mechanism of failure of concrete. The actual failure paths usually follow the interfaces of the largest aggregate particles and cut through the cement paste, and occasionally also through the aggregate particles themselves [16].

As in the concrete, the failure paths usually follow the interfaces of the polystyrene aggregate particles and cut through the cement paste and the aggregate particles themselves. Under compression, the cracks are approximately parallel to the applied load but some cracks form at an angle to the applied load (Figure 1). The parallel cracks are caused by a localized tensile stress in a direction normal to the compressive load; the inclined cracks occur due to collapse caused by the development of shear planes. It should be noted that the fracture patterns of Compression test are for direct stresses only [16].

In the flexure test, the maximum tensile stress is reached in the bottom fibre of a test beam so the cracks are vertical and are near the point of application of the load (Figure 2). In the Tensile test, the top surface is subjected to a compression state, while the lower surface is subjected to traction. The concentration of stress at the crack tip is, in fact, threedimensional but the greatest weakness is when the orientation of a crack is normal to the direction of the applied load. 
TABLE 2: Comparative properties of specimen A and B versus reported parameters.

\begin{tabular}{lcccc}
\hline Property & Brick A & Brick B & Burned clay brick [13] & Mortar brick [13] \\
\hline Dimensions: thick, width, and length $(\mathrm{cm})$ & $6,10,20$ & $6,10,20$ & $5.5,11.5,23$ & $18,12,38$ \\
Volumetric weight $\left(\mathrm{kg} / \mathrm{m}^{3}\right)$ & 1568 & 1236 & 1580 & 1890 \\
Average absorption $(\%)$ & 9.3 & 4.3 & 6.92 & 11.16 \\
Compressive strength $(\mathrm{MPa})$ & 9.69 & 1.65 & 0.755 & 25.2 \\
Average rupture stress $(\mathrm{MPa})$ & 2.94 & & 4.69 \\
\hline
\end{tabular}

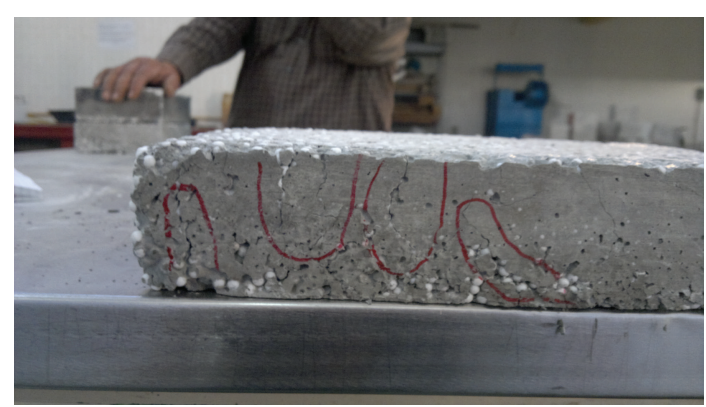

FIGURE 1: Resulting cracks in the brick under Compression test.

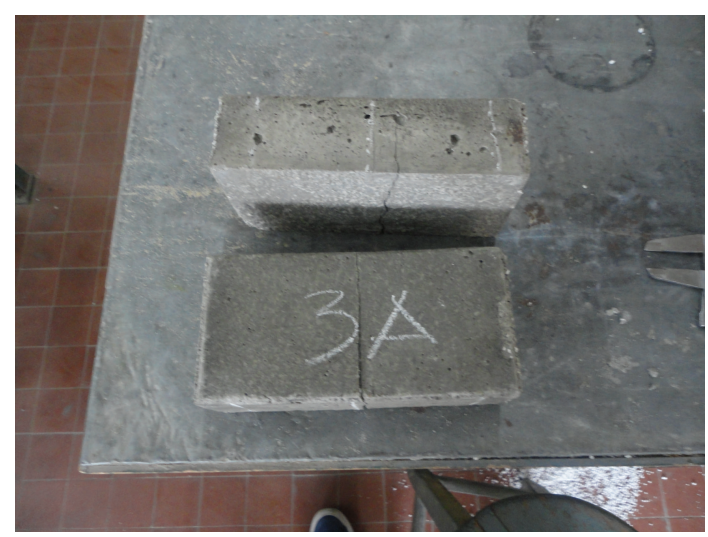

Figure 2: Resulting cracks in the brick under Tensile test.

In a truly brittle material (uniform distribution stress), the energy released by the onset of crack propagation is sufficient to continue this propagation, because, as the crack extends, the maximum stress increases and the brittle fracture strength decreases. In consequence, the process accelerates. In the case of nonuniform stress (e.g., in flexure), the propagation of a crack is blocked, additionally, by the surrounding material at a lower stress [16].

Table 2 shows the results of the properties obtained in the specimens. These are compared with parameters reported elsewhere [13]. This table shows that the EP brick is lighter than the other ones, which facilitates their elaboration, production, and transportation. Then, this material has the property of low absorption, which helps to prevent possible moisture in walls. Besides, this material is resistant, since its compressive strength (with semidry EP) is similar to the reported maximum commercial ones, which could possibly exceed using the EP in dry condition. Finally, this material can be four times more flexible than some commercial blocks, which makes it less vulnerable to possible cracks in walls caused by ascending or descending movements of the underlying soil.

The relatively high values of the coefficient of variation (Table 1) in the test depended on the type of test and the number of data. Absorption and Compression test have similar values of the coefficient of variation; that is, we see the same range of error when performing the test, which can be decreased by increasing the number of tests. Then, Tensile test shows two very different coefficients of variation mainly due to the completion of the test that requires great precision and care. In this test we noticed that the specimen $\mathrm{A}$ has greater error than B because A was tested first. However, all the data of all properties were higher than the reference values in Table 2.

Both materials (A and B) do not have the same time and amount of polystyrene. The specimen A has the complete initial variables and $\mathrm{B}$ does not. Therefore they cannot be comparable between them. So, in this work we report and analyze the properties acquired in the specimen $\mathrm{A}$ and then, the properties acquired in the specimen $B$ (with reference to the specimen A) because even though this material has its incomplete initial variables becomes significant properties precisely because of this situation. Finally both specimens were better than the reference materials in Table 2 .

\section{Conclusions}

The brick developed in this research showed efficient mechanical properties and it could be used as masonry in construction since this material meets the required parameters. It composed of recycled expanded polystyrene as aggregate and commercial Portland cement as binder. Unlike most of the works reported in the literature, this mortar does not use pozzolans or additives or additional aggregates.

Unlike concrete (with coarse aggregate), the failure paths always follow the interfaces of the polystyrene aggregate particles and cut through the cement paste and the aggregate particles themselves. The polystyrene brick cracks are similar to reported concrete cracks in the Compression and Tensile test.

In the results of the properties we observed the same range of error when performing the tests, which can be decreased by increasing the number of tests.

Sustainable use of expanded polystyrene in cellular concrete bricks was very favorable regarding to those existing in the market. The obtained material is lighter, which facilitates 
its production and transportation and is less permeable, which helps to avoid moisture formation keeping its strength. In addition, it is more resistant as well as flexible, which makes it less vulnerable to cracking walls caused by ground movements. Finally, this material is cheaper because it uses recyclable material and has properties that prevent its deterioration increasing its lifetime.

We observe that the environmental moisture and EP moisture diminished the resistance properties of brick and increased its density and absorption. We recommend the use of the fully dry EP under a dry environment to obtain the best properties of brick.

\section{References}

[1] S. Chandra and L. Berntsson, Lightweight Aggregate Concrete. Science, Technology and Applications, Noyes Publications, New York, NY, USA, 2003.

[2] K. G. Babu and D. S. Babu, "Behaviour of lightweight expanded polystyrene concrete containing silica fume," Cement and Concrete Research, vol. 33, no. 5, pp. 755-762, 2003.

[3] D. S. Babu, G. K. Babu, and W. Tiong-Huan, "Effect of polystyrene aggregate size on strength and moisture migration characteristics of lightweight concrete," Cement and Concrete Composites, vol. 28, no. 6, pp. 520-527, 2006.

[4] B. Chen and J. Liu, "Properties of lightweight expanded polystyrene concrete reinforced with steel fiber," Cement and Concrete Research, vol. 34, no. 7, pp. 1259-1263, 2004.

[5] D. S. Babu, G. K. Babu, and W. Tiong-Huan, "Properties of lightweight expanded polystyrene aggregate concretes containing fly ash," Cement and Concrete Research, vol. 35, no. 6, pp. 1218-1223, 2005.

[6] W. C. Tang, Y. Lo, and A. Nadeem, "Mechanical and drying shrinkage properties of structural-graded polystyrene aggregate concrete," Cement and Concrete Composites, vol. 30, no. 5, pp. 403-409, 2008.

[7] B. Chen and J. Liu, "Mechanical properties of polymer-modified concretes containing expanded polystyrene beads," Construction and Building Materials, vol. 21, no. 1, pp. 7-11, 2007.

[8] R. Sri Ravindrarajah and A. J. Tuck, "Properties of hardened concrete containing treated expanded polystyrene beads," Cement and Concrete Composites, vol. 16, no. 4, pp. 273-277, 1994.

[9] O. García-Díaz, Mortero de baja densidad con poliestireno reciclado [M.S. thesis], Facultad de Ingeniería, Universidad Autónoma de Querétaro, Querétaro, México, 2011.

[10] "Standard test methods for sampling and testing brick and structural clay tile," ASTM C67-03a, Annual Book of ASTM Standards, 2003.

[11] A. Laukaitis, R. Žurauskas, and J. Keriene, "The effect of foam polystyrene granules on cement composite properties," Cement and Concrete Composites, vol. 27, no. 1, pp. 41-47, 2005.

[12] K. Miled, K. Sab, and R. le Roy, "Particle size effect on EPS lightweight concrete compressive strength: experimental investigation and modelling," Mechanics of Materials, vol. 39, no. 3, pp. 222-240, 2007.

[13] A. Tena, A. Juárez, and V.H. Salinas, "Resistencia y deformación de muros de mampostería combinada y confinada sujetos a cargas laterales," Revista de Ingeniería Sísmica, vol. 76, pp. 2960, 2007.
[14] WeatherOnline Ltd, 1999-2013, Weather in Rosario, Argentina, August 2012, http://www.woespana.es.

[15] V. K. Alilou and M. Teshnehlab, "Prediction of 28-day compressive strength of concrete on the third day using artificial neural networks," International Journal of Engineering, vol. 3, no. 6, pp. 565-576, 2010.

[16] A. M. Neville and J. J. Brooks, Concrete Technology, Prentice Hall, 2nd edition, 2010. 

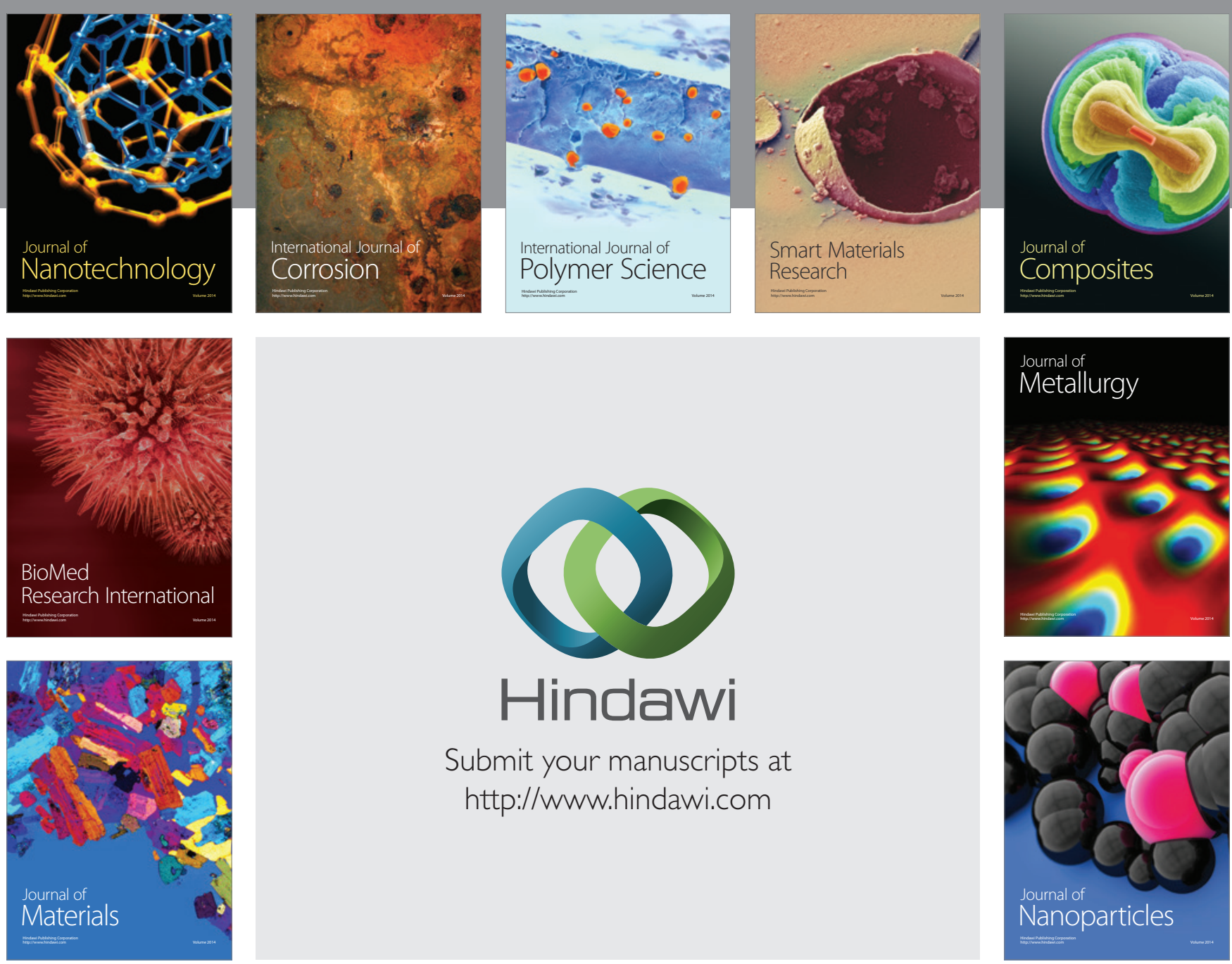

Submit your manuscripts at http://www.hindawi.com
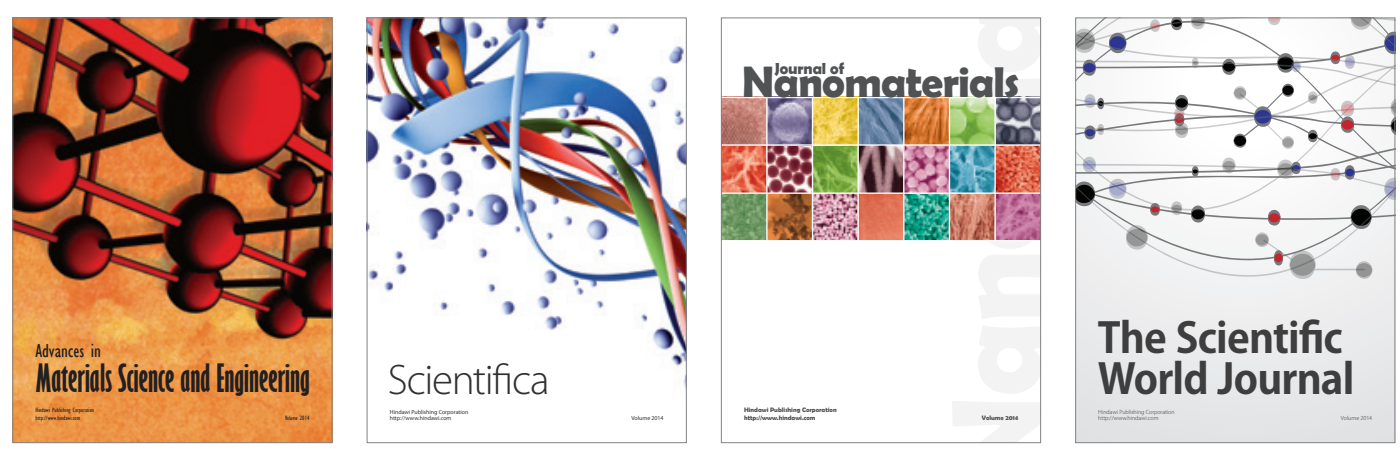

\section{The Scientific World Journal}
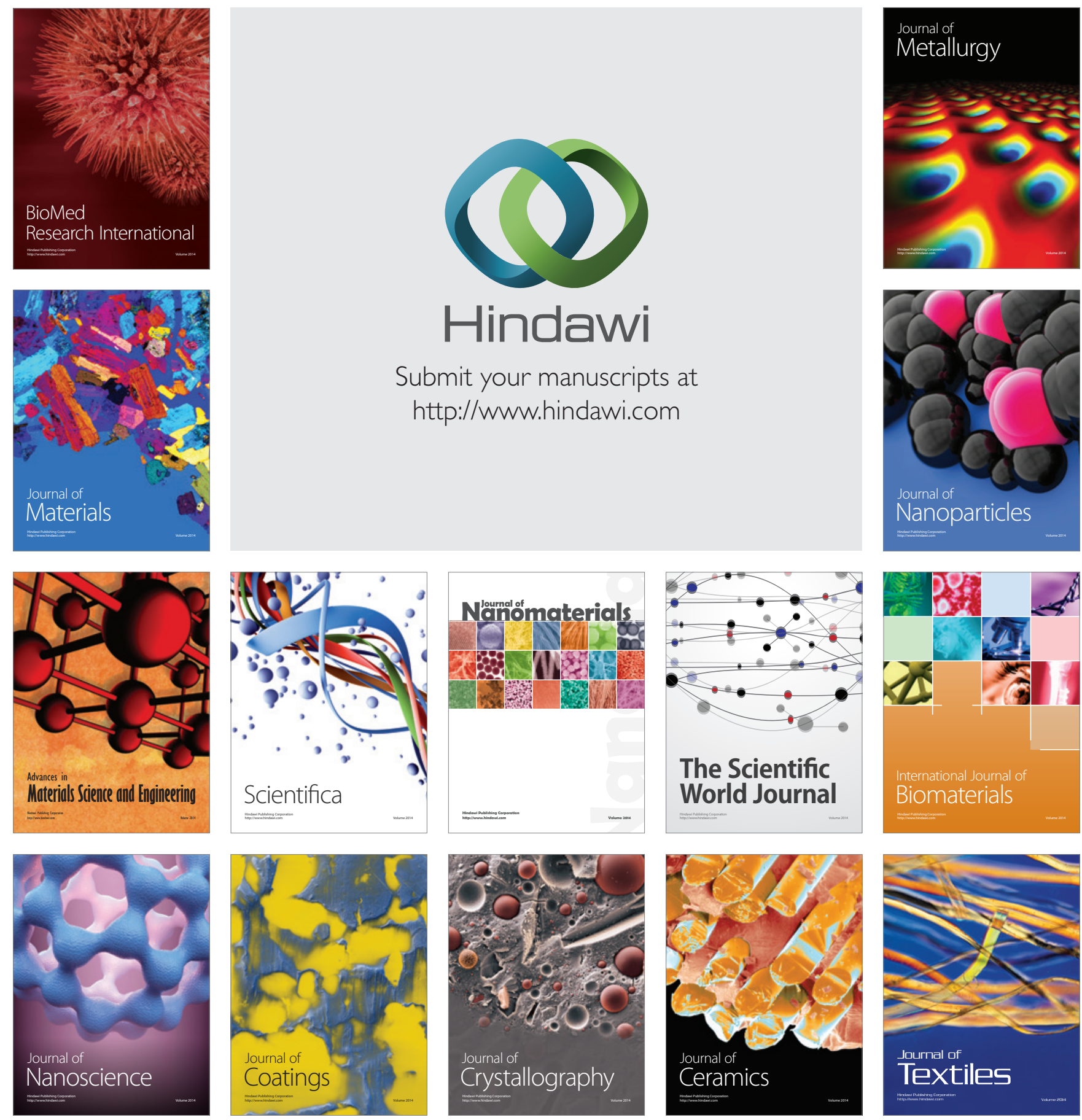